\title{
НОВИЙ МЕТОД ПІДИЛЕННЯ СЕКРЕТНОСТІ ПІНГ-ПОНГ ПРОТОКОЛУ З ПАРАМИ ПЕРЕПЛУТАНИХ КУТРИТІВ
}

\begin{abstract}
Запропоновано новий метод підсилення секретності пінг-понг протоколу з парами переплутаних кутритів, який дозволяє підвищити ефективність його роботи. Розроблено генератор тритових послідовностей, за допомогою якого формується тритова ключова послідовність, що використовується в методі підсилення секретності.

Ключові слова: квантова криптографія, пінг-понг протокол, стійкість протоколу, підсилення секретності, кутрит, генератор трійкових послідовностей.
\end{abstract}

Вступ. Внаслідок масової інформатизації збільшуються обсяги електронних інформаційних ресурсів, які потребують все більш досконалих методів захисту. Найбільш розповсюджені 3 них направлені на збереження конфіденційності та, здебільшого, забезпечуються криптографічними методами i засобами захисту. Проте, більшість традиційних криптографічних методів базується на складності вирішення певних математичних задач, які у зв'язку 3 швидким розвитком обчислювальних засобів (суперкомп'ютери, квантові комп'ютери, GRID-технології тощо) в майбутньому можуть бути розв'язані. Ймовірною альтернативою можуть бути методи квантової криптографії (КК), що є найбільш розвинутим напрямком квантової теорії інформації. Основна задача КК полягає у створенні каналу передачі інформації, абсолютна захищеність якого буде гарантуватись фундаментальними законами природи (квантової механіки), що дозволяють зафіксувати будь-яку спробу проникнення ззовні [1-3]. Однак, робота систем захисту інформації на базі квантових протоколів потребує не лише використання самих протоколів, а й паралельного використання засобів класичної криптографії та завадостійкого кодування, оскільки, не менш важливими є виправлення помилок та підсилення секретності [3].

Значний інтерес серед наукової спільноти викликають, зокрема, протоколи квантового прямого безпечного зв'язку (КПБЗ) $[1,2,4,5]$, характерною особливістю яких є відсутність будь-яких криптографічних перетворень (таким чином вирішена проблема розподілу ключів шифрування, що є дуже актуальною в традиційній криптографії). Одним із найпоширеніших методів КПБЗ є пінг-понг протокол $[1,6]$, який не потребує великого об'єму квантової пам'яті та може використовуватися в існуючих системах захисту інформації [7]. Однак, оригінальний варіант протоколу не зовсім придатний до практичного застосування в системах КК, так як не відповідає в повній мірі вимогам до сучасних систем зв'язку. 3 огляду на це, розроблено цілий ряд методів $[2,5,6,8]$ підвищення ефективності даного протоколу. Проте, їх не можна вважати досконалими, тому роботи, пов'язані 3 підвищенням ефективності пінг-понг протоколу, не втратили своєї актуальності.

Метою роботи є підвищення ефективності роботи пінг-понг протоколу з парами переплутаних кутритів. Під ефективністю, у даному випадку, будемо мати на увазі підвищення стійкості та швидкодії протоколу.

\section{1. Метод підсилення безпеки пінг-понг протоколу 3 парами повністю переплутаних кутритів}

Пінг-понг протокол має два режими роботи, а саме, режим передачі повідомлення та режим контролю підслуховування $[1,9,10]$. У якості кубітів у оригінальному варіанті пінгпонг протоколу використовуються фотони, максимально переплутані за їх поляризаційними ступенями свободи (стани Белла). Інформація кодується фазою переплутаних кубітів. Оскільки тільки один кубіт передається від відправника - Боба до приймача - Аліси (пінг), а потім назад від Аліси до Боба (понг), закодована інформація не може бути вилучена зміною стану цього одного кубіту. Декодування стає можливим лише при виконанні вимірювання в базисі Белла обох кубітів, що дозволяє визначити їх кореляцію один з одним. У режимі 
контролю підслуховування легітимні користувачі аналізують рівень помилок, якщо цей рівень перевищує допустимий, то користувачі переривають сеанс зв'язку.

У початковому варіанті протоколу кожний кубіт, що передається (один з переплутаної пари), використовується для кодування одного класичного біту. На сьогодні, існують різні модифікації протоколу $[2,5,6,8]$, які, використовуючи квантове надщільне кодування та багатовимірні квантові системи - кудити (кутрити, кукварти і т.д.), дозволяють підвищити інформаційну місткість протоколу. Різні атаки, як на оригінальний пінг-понг протокол, так $\mathrm{i}$ на його вдосконалені варіанти, були розглянуті в ряді робіт [11-15]. Зокрема, була проаналізована атака з використанням допоміжних квантових систем (загальна некогерентна атака) на різні варіанти пінг-понг протоколу, в тому числі на протокол 3 парами кутритів [11]. За такої атаки Єва може одержати деяку кількість інформації, перш ніж ії атака буде виявлена $[11,14,15]$ - так звана асимптотична стійкість (недолік у порівнянні 3 абсолютно стійкими системами квантового розподілу ключів [4]).

У роботі [9] запропоновано неквантовий метод підсилення асимптотичної стійкості пінг-понг протоколу з парами повністю переплутаних кутритів, який полягає в наступному:

1) Перед передачею Аліса розбиває своє трійкове повідомлення розміром $m$ на $l$ блоків деякої фіксованої довжини $r$, які позначає як $a_{i}(i=\overline{1, l})$.

2) Потім Аліса генерує для кожного $a_{i}$ випадкову оборотну трійкову матрицю $M_{i}$ розміру $r \times r$.

3) Після чого множенням матриці на блок даних утворює нове повідомлення: $b_{i}=M_{i} a_{i}$.

4) Отримані в результаті блоки $b_{i}$ Аліса передає квантовим каналом з використанням пінг-понг протоколу, при цьому легітимні користувачі аналізують рівень помилок у режимі контролю підслуховування протоколу $[9,10,16]$.

5) Якщо рівень помилок, проаналізований в п.4, не перевищує допустимий, то після завершення квантової передачі матриці $M_{i}$ передаються Бобові звичайним (не квантовим) каналом.

6) Боб обертає отримані матриці.

7) Після чого Боб одержує вихідне повідомлення множенням оберненої матриці на отримане від Аліси квантовим каналом повідомлення: $a_{i}=M_{i}^{-1} b_{i}$.

Навіть якщо Єві вдалося би перехопити один (або більше) із блоків $a_{i}$, залишившись не виявленою, то, не знаючи використаних матриць $M_{i}$, вона не може встановити вихідні блоки $a_{i}$. Для забезпечення високого рівня стійкості, довжина блока $r$ і відповідний розмір матриць $M_{i}(r \times r)$ повинен обиратися так, щоб імовірність успішної атаки Єви $s$ після передачі одного блока $a_{i}$ була нехтовно малою величиною. Значення параметрів $r$ та $s$ розраховуються згідно роботи [9].

Недоліком описаного методу підсилення секретності є те, що для передачі всього повідомлення генерується та використовується дуже велика кількість випадкових, оборотних над полем Галуа, тритових матриць, що потребує великих часових та ресурсних затрат. Для наглядного розуміння в табл. 1 наведено розмір тритових матриць в залежності від загального розміру повідомлення $m$ та параметру $r .3$ таблиці видно, що для передачі повідомлення розміром $m$ квантовим каналом потрібно використовувати матриці загальним розміром $r \cdot m$ тритів. Крім того, в роботі [9] взагалі не описано як саме генеруються тритові матриці, тому не можливо оцінити їх псевдовипадковість.

Для розуміння загальних розмірів даних в бітах переведемо загальний розмір 3 трійкової системи числення в двійкову: 100000000 тритів приблизно дорівнюють 20 МБ (якщо переводити кожні 20 тритів у 32 біти). Тому, загальний розмір матриць $M_{i}$ при $r=28$ 
становитиме 560 МБ, які спочатку потрібно згенерувати, виконати множення $M_{i}$ на $a_{i}$, потім передати класичним каналом, а наприкінці обернути та виділити $3 b_{i}-a_{i}$, що займе занадто багато часу.

Загальний розмір матриць $M_{i}$

Таблиця 1

\begin{tabular}{|l|r|r|r|r|r|r|r|}
\hline & \multicolumn{8}{|c|}{ Загальний розмір повідомлення $m$ в тритах } \\
\cline { 2 - 8 } & 100 & 1000 & 10000 & 100000 & 1000000 & 10000000 & 100000000 \\
\hline$r=4$ & 400 & 4000 & 40000 & 400000 & 4000000 & 40000000 & 400000000 \\
\hline$r=8$ & 832 & 8000 & 80000 & 800000 & 8000000 & 80000000 & 800000000 \\
\hline$r=12$ & 1296 & 12096 & 120096 & 1200096 & 12000096 & 120000096 & 1200000096 \\
\hline$r=16$ & 1792 & 16128 & 160000 & 1600000 & 16000000 & 160000000 & 1600000000 \\
\hline$r=20$ & 2000 & 20000 & 200000 & 2000000 & 20000000 & 200000000 & 2000000000 \\
\hline$r=24$ & 2880 & 24192 & 240192 & 2400192 & 24000192 & 240000192 & 2400000192 \\
\hline$r=28$ & 3136 & 28224 & 280672 & 2800448 & 28000560 & 280000112 & 2800000336 \\
\hline
\end{tabular}

Пропонується використовувати замість матриць $M_{i}$ розміром $r \times r$ ключову трійкову послідовність $k_{i}$ розміром $r$. Повідомлення $b_{i}$ буде вираховуватись за формулою $b_{i}=k_{i}+a_{i}$, а $a_{i}$ - за формулою $a_{i}=b_{i}-k_{i}$, де операції "+" та "-" - означають відповідно операції потритового додавання та віднімання за модулем 3. Ключова трійкова послідовність $k_{i}$ буде вироблятись за допомогою генератора псевдовипадкових трійкових послідовностей, та 96-тритового ключа $K$. Після завершення квантової передачі, у випадку відсутності атаки, замість передачі матриць $M_{i}$ буде передаватись ключ $K$ звичайним каналом зв'язку.

У п.2 даної роботи описано принцип роботи розробленого генератора тритових послідовностей, який пропонується використовувати у цьому методі підсилення секретності для генерування ключової послідовності $k_{i}$. При необхідності він може бути змінений на інший.

Загальна схема запропонованого неквантового методу підсилення безпеки пінг-понг протоколу з парами повністю переплутаних кутритів наведена на рис. 1.

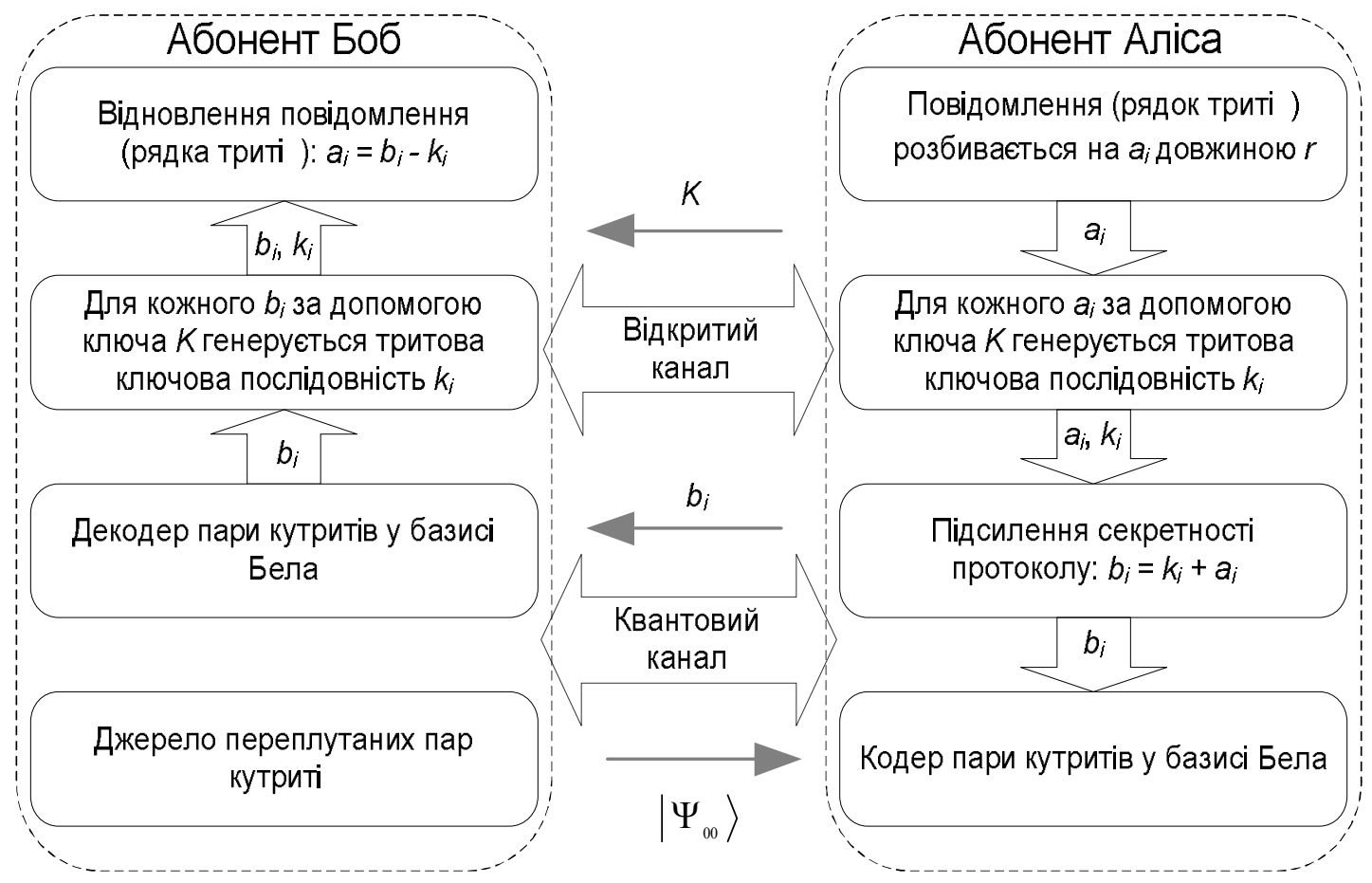

Рис.1. Загальна схема запропонованого методу підсилення безпеки пінг-понг протоколу з парами повністю переплутаних кутритів 
Проаналізуємо швидкість роботи існуючого [9] та запропонованого методу підсилення секретності пінг-понг протоколу. Нехай необхідно передати за допомогою пінгпонг протоколу повідомлення довжиною $m=r \cdot l$ - трит, де $r-$ розмір блоку даних, a $l$ кількість таких блоків. Позначимо як $t_{1}-$ час генерування ключових даних. Для існуючого методу підсилення секретності - час генерування оборотних матриць $M_{i}(i=\overline{1, l})$ розміром $r \times r$, а для запропонованого - час генерування ключової послідовності $k_{i}$ розміром $r$. Тоді $t_{2}$ - час утворення повідомлення $b_{i}$, а $t_{3}$ - час передачі повідомлень $b_{i}$ по квантовому каналі за пінг-понг протоколом. Позначимо як $t_{4}$ - час передачі оборотних матриць $M_{i}$ по класичному каналі для існуючого методу підсилення секретності, а для запропонованого час передачі 96 тритового ключа $K$. Час утворення оборотних матриць $M_{i}^{-1}$ для існуючого методу підсилення або час генерування ключової послідовності $k_{i}$ розміром $r$ для запропоновано методу підсилення секретності позначимо як $t_{5}$. Тоді $t_{6}$ - час відновлення повідомлення $a_{i}$. У табл. 2. розраховано $t_{j}(j=\overline{1,6})$ в залежності від швидкості генерування тритових послідовностей $V_{g e n}$, швидкостей передачі повідомлень квантовим $V_{k v}$ i класичним каналом $V_{k l}$ та швидкості виконання операцій множення та додавання в полі $G F(3) V_{x}$.

Загальний час роботи системи

Таблиця 2

\begin{tabular}{|c|c|c|c|c|c|c|}
\hline $\begin{array}{c}\text { Методи } \\
\text { підсилення } \\
\text { безпеки пінг- } \\
\text { понг протоколу } \\
\end{array}$ & $t_{1}$, сек & $t_{2}$, сек & $t_{3}$, сек & $t_{4}$, сек & $t_{5}$, сек & $t_{6}$, сек \\
\hline Існуючий & $\frac{l \cdot r^{2}}{V_{g e n}}$ & $\frac{l \cdot\left(2 r^{2}-r\right)}{V_{x}}$ & $\frac{l \cdot r}{V_{k v}}$ & $\frac{l \cdot r^{2}}{V_{k l}}$ & $\frac{l \cdot\left(4 r^{3}-4 r^{2}\right)}{V_{x}}$ & $\frac{l \cdot\left(2 r^{2}-r\right)}{V_{x}}$ \\
\hline Запропонований & $\frac{l \cdot r}{V_{\text {gen }}}$ & $\frac{l \cdot r}{V_{x}}$ & $\frac{l \cdot r}{V_{k v}}$ & $\frac{96}{V_{k l}}$ & $\frac{l \cdot r}{V_{\text {gen }}}$ & $\frac{l \cdot r}{V_{x}}$ \\
\hline
\end{tabular}

Швидкість роботи кожного з методів буде визначатися за такою формулою:

$$
V=\frac{r \cdot l}{t_{1}+t_{2}+t_{3}+t_{4}+t_{5}+t_{6}} \text { трит/сек. }
$$

Оскільки швидкість роботи протоколу залежить від $V_{g e n}, V_{k v}, V_{k l}, V_{x}, r$ та $l$, то для більш конкретної оцінки швидкостей обох методів підсилення було вирішено провести моделювання роботи протоколу з різними показниками $V_{g e n}, V_{k v}, V_{k l}, V_{x}, r$ та $l$. Для цього була запропонована модель, яка складається таких етапів:

1. На початку фіксуються базові параметри протоколу: $V_{k v}, V_{k v}, V_{x}, V_{g e n}$.

2. Обирається не квантовий спосіб підсилення безпеки пінг-понг протоколу.

3. Обирається довжина повідомлення $m\left(10^{4}, 10^{5}, 10^{6}\right)$ у тритах.

4. Обирається параметр $r(4,12,20)$ та розраховується параметр $l$.

5. Після чого для обраних параметрів $V_{g e n}, V_{k v}, V_{k l}, V_{x}, r$ та $l$ розраховується загальна швидкість роботи пінг-понг протоколу, яку заносять у таблицю для подальшої обробки.

Результати моделювання наведені в табл. 3, причому для моделювання роботи протоколу обрано 5 різних комбінацій параметрів $V_{g e n}, V_{k v}, V_{k l}, V_{x}$ : 
1. $V_{\text {gen }}=10^{8}$ трит/ сек, $V_{k l}=V_{x}=V_{k v}=10^{6}$ трит $/$ сек.

2. $V_{x}=10^{8}$ трит/ сек, $V_{k l}=V_{g e n}=V_{k v}=10^{6}$ трит/ сек.

3. $V_{k v}=10^{8}$ трит/ сек, $V_{k l}=V_{x}=V_{g e n}=10^{6}$ трит/ сек.

4. $V_{k l}=10^{8}$ трит/ сек, $V_{g e n}=V_{x}=V_{k v}=10^{6}$ трит/ сек.

5. $V_{g e n}=V_{k l}=V_{x}=V_{k v}=10^{6}$ трит/ сек.

Швидкість роботи методів підсилення секретності в трит/сек

Таблиця 3

\begin{tabular}{|c|c|c|c|c|c|c|c|c|c|c|}
\hline \multirow{2}{*}{$\begin{array}{l}\text { Комбінація } \\
\text { параметрів }\end{array}$} & \multirow{2}{*}{$\begin{array}{c}\text { Методи } \\
\text { підсилення }\end{array}$} & \multicolumn{3}{|c|}{$m=10000$ трит } & \multicolumn{3}{|c|}{$m=100000$ трит } & \multicolumn{3}{|c|}{$m=1000000$ трит } \\
\hline & & $\begin{array}{l}r=4, \\
l=2500\end{array}$ & $\begin{array}{l}r=12, \\
l=834\end{array}$ & $\begin{array}{l}r=20 \\
l=500\end{array}$ & $\begin{array}{l}r=4, \\
l=25000\end{array}$ & $\begin{array}{l}r=12, \\
l=8334\end{array}$ & $\begin{array}{l}r=20, \\
l=5000\end{array}$ & $\begin{array}{l}r=4, \\
l=250000\end{array}$ & $\begin{array}{l}r=12, \\
l=83334\end{array}$ & $\begin{array}{l}r=20, \\
l=50000\end{array}$ \\
\hline \multirow[t]{2}{*}{1} & IcH. & 14916 & 1703 & 617 & 14916 & 1703 & 617 & 14916 & 1703 & 617 \\
\hline & Запроп. & 330076 & 33076 & 33076 & 331020 & 331020 & 331020 & 331115 & 331115 & 331115 \\
\hline \multirow[t]{2}{*}{2} & IcH. & 103950 & 32530 & 17550 & 103950 & 32530 & 17550 & 103950 & 32530 & 17550 \\
\hline & Запроп. & 330076 & 330076 & 330076 & 331020 & 331020 & 331020 & 331115 & 331115 & 331115 \\
\hline \multirow[t]{2}{*}{3} & IcH. & 14263 & 1672 & 610 & 14263 & 1672 & 610 & 14263 & 1672 & 610 \\
\hline & Запроп. & 248780 & 248781 & 248781 & 249316 & 249316 & 249316 & 249370 & 249370 & 249370 \\
\hline \multirow[t]{2}{*}{4} & IсH. & 14916 & 1703 & 617 & 14916 & 1703 & 617 & 14916 & 1703 & 617 \\
\hline & Запроп. & 199996 & 199996 & 199996 & 199999 & 199999 & 199999 & 199999 & 199999 & 199999 \\
\hline \multirow[t]{2}{*}{5} & IcH. & 14084 & 1669 & 610 & 14084 & 1669 & 610 & 14084 & 1669 & 610 \\
\hline & Запроп. & 199616 & 199617 & 199616 & 199961 & 199961 & 199961 & 199996 & 199996 & 199996 \\
\hline
\end{tabular}

Як видно 3 табл. 3 при збільшені параметра $r$ швидкість запропонованого методу підсилення секретності не змінюється, а швидкість методу [9] зменшується у 6-24 рази (в залежності від параметрів $\left.V_{g e n}, V_{k v}, V_{k l}, V_{x}\right)$. При збільшені параметру $l$ швидкості методів практично не змінюються. Швидкість роботи запропонованого методу у порівняні 3 існуючим збільшується у 3 - 536 разів і залежить від параметрів $V_{g e n}, V_{k v}, V_{k l}, V_{x}, r$ та $l .3$ огляду на це, можна зробити висновок, що використання запропонованого методу підсилення секретності, дозволить підвищити швидкість пінг-понг протоколу.

\section{2. Генератор трійкових послідовностей}

Принцип роботи розробленого генератора полягає у наступному:

1. На вхід розробленого генератора подається 96 тритовий ключ $K$, загальний розмір повідомлення $m$ та розмір блоку даних $r$.

2. Далі розраховується параметр $n \in \mathrm{Z}$, який означає, яку кількість разів необхідно використовувати циклову функцію для генерування послідовності розміром $m: n=m / 48+1$.

3. Ключ $K$ розбивається на 4 частини $K_{1}, K_{2}, K_{3}, K_{4}$ по 24 трита. 
4. За допомогою циклової функції, формується трійкова послідовність $y_{i}(i=1, \ldots, n)$. На вхід циклової функції подаються 24-тритні допоміжні змінні $A, B, C, D, E, F, Y_{1}, Y_{2}$ (початкові значення яких наведені в табл. 4, вагові коефіцієнти тритів зростають зліва на право) та частини ключа $K_{1}, K_{2}, K_{3}, K_{4}$, за допомогою яких формується вихідна тритова послідовність. У цикловій функції для кожного $i=1, \ldots, n$, виконуються такі операції:

4.1. Розраховується нове значення $A: \quad$ 4.1.1. $A=\operatorname{Sbox}\left(A\langle+\rangle K_{1}\right)+D$; 4.1.2. $A=\operatorname{Left}_{24}\left(\operatorname{MatrixMult}(A), K_{4}\right)$.

4.2. Розраховується нове значення $B: \quad$ 4.2.1. $B=\operatorname{Sbox}\left(B+K_{2}\right)\langle+\rangle E$; 4.2.2. $B=$ Right $_{24}\left(\right.$ MatrixMult $\left.(B), K_{3}\right)$.

4.3. Розраховується нове значення $C: \quad$ 4.3.1. $C=\operatorname{Sbox}\left((C\langle+\rangle F)+Y_{2}\right)$; 4.3.2. $C=\operatorname{Left}_{24}(\operatorname{MatrixMult}(C), D)$.

4.4. Розраховується нове значення $K_{1}: \quad$ 4.4.1. $K_{1}=\operatorname{Sbox}\left(K_{1}+A\right)\langle+\rangle E$; 4.4.2. $K_{1}=\operatorname{Sbox}\left(\operatorname{MatrixMult}\left(K_{1}\right)+Y_{1}\right)$.

4.5. Розраховується нове значення $K_{2}: \quad$ 4.5.1. $K_{2}=\operatorname{Sbox}\left(K_{2}\langle+\rangle B\right)\langle+\rangle F$; 4.5.2. $K_{2}=\operatorname{Sbox}\left(\operatorname{MatrixMult}\left(K_{2}\right)+Y_{2}\right)$.

4.6. Розраховується нове значення $Y_{1}$ : 4.6.1. $Y_{1}=\operatorname{Sbox}\left(Y_{1}\langle+\rangle K_{1}\right)$; 4.6.2. $Y_{1}=$ MatrixMult $\left(\operatorname{Left}_{24}\left(Y_{1}, B\right)\right)$; 4.6.3. $Y_{1}=\operatorname{Sbox}\left(Y_{1}+K_{2}\right)$.

4.7. Розраховується нове значення $D: \quad$ 4.7.1. $D=\operatorname{Sbox}\left(D\langle+\rangle K_{3}\right)+A$; 4.7.2. $D=\operatorname{Left}_{24}\left(\operatorname{MatrixMult}(D), K_{2}\right)$.

4.8. Розраховується нове значення $E: \quad$ 4.8.1. $E=\operatorname{Sbox}\left(E+K_{4}\right)\langle+\rangle B$; 4.8.2. $E=\operatorname{Right}_{24}\left(\operatorname{MatrixMult}(E), K_{1}\right)$.

4.9. Розраховується нове значення $F: \quad$ 4.9.1. $F=\operatorname{Sbox}\left((F\langle+\rangle C)+Y_{1}\right)$;

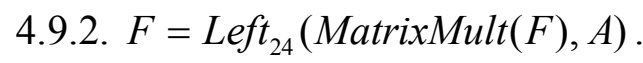

4.10. Розраховується нове значення $\quad K_{3}: \quad$ 4.10.1. $K_{3}=\operatorname{Sbox}\left(K_{3}+D\right)\langle+\rangle B$; 4.10.2. $K_{3}=\operatorname{Sbox}\left(\operatorname{MatrixMult}\left(K_{3}\right)+Y_{2}\right)$.

4.11. Розраховується нове значення $K_{4}: \quad$ 4.11.1. $K_{4}=\operatorname{Sbox}\left(K_{4}\langle+\rangle E\right)\langle+\rangle C$; 4.11.2. $K_{4}=\operatorname{Sbox}\left(\operatorname{MatrixMult}\left(K_{4}\right)+Y_{1}\right)$.

4.12. Розраховується нове значення $Y_{2}: \quad$ 4.12.1. $Y_{2}=\operatorname{Sbox}\left(Y_{2}\langle+\rangle K_{3}\right)$; 4.12.2. $Y_{2}=\operatorname{MatrixMult}\left(\operatorname{Left}_{24}\left(Y_{2}, E\right)\right) ;$ 4.12.3. $Y_{2}=\operatorname{Sbox}\left(Y_{2}+K_{4}\right)$.

4.13. Розраховується 48-тритне значення $y_{i}$ за допомогою конкатенації $Y_{1}$ та $Y_{2}$ : $y_{i}=Y_{1} \mid Y_{2}$.

5. 3 утвореної послідовності $y_{i}(i=1, \ldots, n)$ формується послідовність довжиною $m$. 
Отримана послідовність розділяється на $l$ блоків довжиною $r$, які і утворять вихідну ключову послідовність тритів $k_{j}(j=1, \ldots, l)$.

Початкові значення змінних $A, B, C, D, E, F, Y_{1}, Y_{2}$ Таблиця 4

\begin{tabular}{|l|l|l|l|}
\hline$A$ & 012012012012012012012021 & $D$ & 211020112200201220101012 \\
\hline$B$ & 122010120022012112021010 & $E$ & 020211221022101021012100 \\
\hline$C$ & 221102101201120100210202 & $F$ & 100120201101122112002022 \\
\hline$Y_{1}$ & 022102012010211212100102 & $Y_{2}$ & 212001020110212021001212 \\
\hline
\end{tabular}

Опишемо операції, які використовуються в запропонованому генераторі:

1. Операція "+" - потритове додавання за модулем 3.

2. Операція "〈+〉" - додавання за модулем $3^{24}$.

3. $\operatorname{Right}_{24}(X, Y)$ - циклічний зсув вправо числа $X$ на $Y$ разів.

4. $\operatorname{Left}_{24}(X, Y)$ - циклічний зсув вліво числа $X$ на $Y$ разів.

5. $\operatorname{Sbox}(X)$ - нелінійна заміна кожних шести тритів числа $X$ на відповідне їм значення таблиці підстановок. Для виконання операції число $X$ розбивається на чотири частин по 6 тритів $x_{i}(i=0, \ldots, 3)$. Виконання заміни через таблицю підстановок полягає в тому, що значення $x_{i}$ задає адресу в таблиці підстановки, по якій необхідно взяти нове значення $x_{i}$. Запропонований $S$-блок побудований за допомогою обрахунку зворотного елементу поля $(X)^{-1} \in G F\left(3^{6}\right)$ з подальшим виконанням афінного перетворенням над полем $G F(3)$ : $S(X)=M \cdot(X)^{-1}+V$, де $X, V \in G F\left(3^{6}\right)$, а $M$ - квадратна не вироджена матриця над полем $G F(3)$ розміром $6 \times 6$ (вагові коефіцієнти тритів зростають зверху до низу і зліва на право, тобто елемент $M[0][0]$, який знаходиться в верхньому лівому куті, відповідає молодшому розряду):

$$
M=\left(\begin{array}{llllll}
1 & 2 & 0 & 1 & 1 & 2 \\
2 & 1 & 2 & 0 & 1 & 1 \\
1 & 2 & 1 & 2 & 0 & 1 \\
1 & 0 & 2 & 1 & 2 & 0 \\
0 & 1 & 0 & 2 & 1 & 2 \\
2 & 0 & 1 & 1 & 2 & 1
\end{array}\right), V=\left(\begin{array}{l}
0 \\
2 \\
2 \\
1 \\
0 \\
2
\end{array}\right)
$$

Кінцеве поле $G F\left(3^{6}\right)$ фіксується кільцем многочленів 3 операціями за модулем незвідного многочлена $m(x)=x^{6}+x+2$.

6. MatrixMult $(X)-$ множення трійкової матриці Mat розміром $24 \times 24$ трита на $X$ (представлений у вигляді стовпчика) над полем $G F(3)$, дана матриця побудована на основі такого закону: $\operatorname{Mat}[i][j]=U[(j+24-i) \bmod 24]$, де $i, j=0, \ldots, 23$, а масив $U=\{1,0,2$, $2,1,0,2,0,1,1,1,2,0,1,2,1,0,2,0,0,1,2,0,2\}$. 
Проте, перевірити псевдовипадковість, сформованої запропонованим генератором, тритової послідовності складно, оскільки не існує програмних комплексів для перевірки випадковості трійкових послідовностей таких, наприклад, як статистичні тести DIEHARD чи NIST STS для бінарних послідовностей. Тому, для початку було вирішено перевірити послідовність, утворену за допомогою розробленого генератора, так званим частотним тестом, який полягає у перевірці відхилення загальної кількості нулів, одиниць та двійок послідовності від ідеального значення (1/3 від загальної кількості тритів). Для цього було розроблено відповідне програмне забезпечення, за допомогою якого генерувалась послідовність заданого розміру запропонованим генератором та виконувалась перевірка відхилення загальної кількості нулів, одиниць та двійок послідовності від ідеального значення. Якщо максимальне відхилення менше 1\% від ідеального значення, то тест вважався пройденим.

Для експерименту було обрано 3 різні ключі $K_{j}(j=1, \ldots, 3)$ (табл. 5), за допомогою яких формувались трійкові послідовності розміром $48 \cdot 10^{i}(i=3, \ldots, 6)$ тритів. Дані результати 3 максимальним відхиленням наведені в табл. 6, з якої слідує проходження частотного тесту.

Ключі які використовувались в експерименті

Таблиця 5

\begin{tabular}{|l|l|}
\hline$K_{1}$ & 100000000000000000000000000000000000000000000000000000000000000000000000000000000000000000000000 \\
\hline$K_{2}$ & 211102212200201220221011122020210001122112112022001210100122110210010201120110122012202122011020 \\
\hline$K_{3}$ & 102112210011121201202012201120202110012210111121120202110222200220021202021110002112112102002021 \\
\hline
\end{tabular}

Результати тестування частотним тестом сформованої трійкової послідовності

Таблиця 6

\begin{tabular}{|c|c|c|c|c|c|c|c|c|c|c|c|}
\hline \multirow{2}{*}{$\begin{array}{c}\text { Розмір } \\
\text { повідом. }\end{array}$} & \multicolumn{3}{|c|}{$K_{1}$} & \multicolumn{3}{|c|}{$K_{2}$} & \multicolumn{3}{|c|}{$K_{3}$} & \multirow{2}{*}{$\begin{array}{c}\text { Макс. } \\
\text { відх. }\end{array}$} & \multirow[t]{2}{*}{ \% відх } \\
\hline & 0 & 1 & 2 & 0 & 1 & 2 & 0 & 1 & 2 & & \\
\hline $48 \cdot 10^{3}$ & 15974 & 15995 & 16031 & 16005 & 16070 & 15925 & 16048 & 16071 & 15881 & 120 & 0,75 \\
\hline $48 \cdot 10^{4}$ & 159920 & 160148 & 159932 & 160402 & 160170 & 159428 & 159885 & 160139 & 159976 & 572 & 0,358 \\
\hline $48 \cdot 10^{5}$ & 1600647 & 1598833 & 1600520 & 1600915 & 1600110 & 1598975 & 1600579 & 1600352 & 1599069 & 1167 & 0,073 \\
\hline $48 \cdot 10^{6}$ & 15998242 & 16001548 & 16000210 & 16002233 & 15999905 & 15997892 & 16001772 & 16001544 & 15996684 & 3316 & 0,021 \\
\hline
\end{tabular}

Однак, перевірка послідовності одним тестом не може гарантувати іiі псевдовипадковість, враховуючи різноманітні параметри послідовності. Для остаточного висновку про псевдовипадковість, сформованої генератором послідовності, потрібно розробити методику та програмне забезпечення для тестування трійкової послідовності на випадковість і провести більш детальне дослідження.

Висновки. У роботі запропоновано новий метод підсилення секретності пінг-понг протоколу з парами повністю переплутаних кутритів, що дало можливість підвищити його швидкодію мінімум у 3 рази в порівняні з відомим методом підсилення секретності. Крім того, розроблено генератор трійкових послідовностей, який в майбутньому може застосовуватись для генерації трійкової ключової послідовності. Проте, цей метод, безумовно, потребує більш детального дослідження - необхідно розробити методику, програмне забезпечення та протестувати на псевдовипадковість згенеровані ним трійкові послідовності.

\section{ЛІТЕРАТУРА}

1. Bostrom K. Deterministic secure direct communication using entanglement / K. Bostrom, T. Felbinger // Physical Review Letters. - 2002. - V. 89, issue 18. - 187902. 
2. Cai Q.-Y. Improving the capacity of the Bostrom-Felbinger protocol / Q.-Y. Cai, B.-W. Li // Physical Review A. - 2004. - V. 69, issue 5. - 054301.

3. Нильсен М. Квантовые вычисления и квантовая информация / М. Нильсен, И. Чанг //. - М. : Мир, 2006. $-824 \mathrm{c}$.

4. Quantum Secure Telecommunication Systems / [Oleksandr Korchenko, Petro Vorobiyenko, Maksym Lutskiy, Yevhen Vasiliu, Sergiy Gnatyuk] // Telecommunications Networks : Current Status and Future Trends / edited by Jesus Hamilton Ortiz. - Rijeka, Croatia : InTech, 2012. — P. 211-236.

5. Василиу Е.В. Пинг-понг протокол с трех- и четырехкубитными состояниями Гринбергера-ХорнаЦайлингера / Е.В. Василиу, Л.Н. Василиу // Труды Одесского политехнического университета. — 2008. Вып. 1(29). - С. 171-176.

6. Васіліу С.В. Пінг-понг протокол з повністю переплутаними станами пар та триплетів тривимірних квантових систем / С.В. Васіліу // Цифрові технології. - 2009, № 5. - С. 18-26.

7. Ostermeyer M. On the implementation of a deterministic secure coding protocol using polarization entangled photons / M. Ostermeyer, N. Walenta // Optics Communications. — 2008. — V. 281, issue 17. — P. 4540-4544.

8. Wang Ch. Quantum secure direct communication with high dimension quantum superdense coding / Ch. Wang, F.-G. Deng, Y.-S. Li [et al] // Physical Review A. - 2005. - V. 71, issue 4. - 044305.

9. Василиу Е.В. Синтез основанной на пинг-понг протоколе квантовой связи безопасной системы прямой передачи сообщений / Е.В. Василиу, С.В. Николаенко // Наукові праці ОНАЗ ім. О.С. Попова. — 2009, № 1. - С. 83-91.

10. Корченко О.Г. Імітаційна модель пінг-понг протоколу з парами переплутаних кутритів у квантовому каналі з шумом / О.Г. Корченко, Є.В. Васіліу, С.О. Гнатюк, В.М. Кінзерявий // Захист інформації. — 2010. №3. - C. 46-56.

11. Василиу Е.В. Анализ атаки пассивного перехвата на пинг-понг протокол с полностью перепутанными парами кутритов / Е.В. Василиу, Р.С. Мамедов // Восточноевропейский журнал передовых технологий. - 2009 , № 4/2 (40). - C. 4-11.

12. Zhang Zh.-J. Improved Wojcik's eavesdropping attack on ping-pong protocol without eavesdropping-induced channel loss / Zh.-J. Zhang, Y. Li, Zh.-X. Man // Physics Letters A. - 2005. - V. 341, issue 5-6. — P. $385-389$.

13. Cai Q.-Y. The «Ping-pong» protocol can be attacked without eavesdropping / Q.-Y. Cai // Physical Review Letters. - 2003. - V. 91, issue 10. - 109801.

14. Deng F.-G. Two-step quantum direct communication protocol using the Einstein-Podolsky-Rosen pair block / F.-G. Deng, G.L. Long, X.-S. Liu // Physical Review A. — 2003. — V. 68, issue 4. — 042317.

15. Василиу Е.В. Стойкость пинг-понг протокола с триплетами Гринбергера-Хорна-Цайлингера к атаке с использованием вспомогательных квантовых систем / Е.В. Василиу // Информатика: Объединенный институт проблем информатики НАН Беларуси. — 2009, № 1 (21) - С. 117-128.

16. Корченко О.Г. Імітаційне моделювання роботи системи квантового прямого безпечного зв'язку із застосуванням завадостійких кодів для кутритів / О.Г. Корченко, С.В. Васіліу, С.О. Гнатюк, В.М. Кінзерявий // Захист інформації. — 2011. — №2 (51). — С. 61-69. 